\title{
Fontan completion timing: is there a "right" season?
}

Laxmi V. Ghimire ${ }^{1,2}$ (1) and Anita J. Moon-Grady ${ }^{3}$

${ }^{1}$ Section of Pediatrics and Section of Cardiology, Department of Medicine, Lakes Region General Hospital, Laconia, NH, USA; ${ }^{2}$ Department of Pediatrics, University of New England, Biddeford, ME, USA and ${ }^{3}$ Division of Pediatric Cardiology, University of California, San Francisco, San Francisco, CA, USA

Cite this article: Ghimire LV and MoonGrady AJ (2020) Fontan completion timing: is there a "right" season? Cardiology in the Young 30: 1549-1550. doi: 10.1017/ S1047951120001766

\section{Received: 24 May 2020}

Accepted: 27 May 2020

First published online: 23 June 2020

\section{Author for correspondence:}

Laxmi V. Ghimire, MD, Section of Pediatrics and Section of Cardiology, Lakes Region General Hospital, Laconia, NH 03246, USA. Tel: +1 (603) 5280995 .

E-mail: laxmivilasg@gmail.com, Ighimire@lrgh.org

\section{Dear Editor,}

We read with interest the research article by Nordmeyer et $\mathrm{al}^{1}$ in a recent issue of Cardiology in the Young. The authors have meticulously analysed important outcome variables in 211 patients and shown that in their experience Fontan surgery during winter months is not associated with higher mortality and morbidity in the early post-operative period. However, as the authors mention, one of the major limitations of this study is its single-centre design. We were curious to know if there were seasonal differences in mortality and post-operative outcomes in children undergoing Fontan surgery across centres in the United States.

Using the multi-centre Kids Inpatient Database from the years 2003, 2006, 2009, and 2012, we identified 5306 cases of Fontan completion surgeries. Median age of Fontan was 3 years (interquartile range: $2-4$ ). A similar number of patients carried a systemic right ventricle diag- (c) The Author(s), 2020. Published by Cambridge University Press. nosis, though the distribution of primary diagnoses was somewhat different: the four most common congenital heart disease by code were hypoplastic left heart syndrome $(34.8 \%, \mathrm{n}$ $=1844)$, common ventricle $(23.3 \%, \mathrm{n}=1234)$, tricuspid atresia $(20.3 \%, \mathrm{n}=1075)$, and double outlet right ventricle $(15.9 \%, \mathrm{n}=841)$. Compared with the Nordmeyer experience, the in-hospital mortality rate was somewhat lower at $2.3 \%$. Respiratory failure rate was $3.5 \%$ and incidence of atrial arrhythmias was $8.2 \%$.

We further compared outcomes between the children undergoing surgery during summer (April-October) versus winter (November-March); data were available in 5041 (95.0\%) cases. Of these, $73.3 \%(n=3694)$ underwent surgery during summer, while $26.7 \%(n=1347)$ underwent Fontan during winter months. Median age at surgery was not different between groups. Similar to the Nordmeyer report, we found no difference in in-hospital mortality, $2.1 \%(\mathrm{n}=79)$ in summer versus $2.3 \%(\mathrm{n}=31)$ in winter $(\mathrm{p}=0.36)$. Post-operative complications including acute respiratory failure, acute kidney injury, and arrhythmias were also similar in winter versus summer (Table 1). Extracorporeal support was needed in $1.5 \%(\mathrm{n}=54)$ of children undergoing surgery in summer and $1.8 \%(n=24)$ in winter, $\mathrm{p}=0.77$. The length of hospitalisation after Fontan procedure was quite similar as well, with a median length of stay of 10 (range, 7-15) days in summer versus 9 (range, $7-15$ ) days in winter, $\mathrm{p}=0.24$.

Thus our results, using a large administrative database in the United States to take a wide-lens view of the question posed by the single-centre team in Germany, bring us to a very similar conclusion - that in-hospital mortality and morbidity for Fontan completion surgery are similar in summer and winter months. Whether aspects of patient selection influence these findings but are not captured will probably never be answered; there may be subtleties in patient counselling, care, and surgical scheduling that are nuanced but important that are not being recognised by the studies extant at present. However, it does seem safe to say that despite clinician biases to the contrary, there is ample clinical evidence that there is no "best" season for Fontan surgery.

\section{CAMBRIDGE UNIVERSITY PRESS}


Table 1. Fontan completion surgery: summer versus winter season.

\begin{tabular}{lccc}
\hline Variables & Summer, \% (n) & Winter, $\%(\mathrm{n})$ & p-Value \\
\hline Total cases & $73.3 \%(3694)$ & $26.7 \%(1347)$ & \\
\hline Female & $41.0 \%(1513)$ & $39.9 \%(536)$ & 0.84 \\
\hdashline Age, years(median, IQR) & $3(2-4)$ & $3(2-4)$ & 0.21 \\
\hline In-hospital mortality & $2.1 \%(79)$ & $2.3 \%(31)$ & 0.36 \\
\hline Respiratory failure & $3.3 \%(122)$ & $4.6 \%(62)$ & 0.43 \\
\hline Acute kidney injury & $3.5 \%(129)$ & $4.0 \%(54)$ & 0.84 \\
\hline Arrhythmias & $9.4 \%(346)$ & $11.4 \%(154)$ & 0.25 \\
\hline Atrial arrhythmias & $7.9 \%(293)$ & $9.4 \%(127)$ & 0.37 \\
\hline ECMO & $1.5 \%(54)$ & $1.8 \%(24)$ & 0.77 \\
\hline LOS, days(median, IQR) & $10(7-15)$ & $9(7-15)$ & 0.24 \\
\hline
\end{tabular}

$\mathrm{p}$-Values were obtained from linear regression model

$\mathrm{ECMO}=$ extracorporeal membrane oxygenation; $\mathrm{IQR}=$ interquartile range; $\mathrm{LOS}=$ length of stay
Acknowledgements. None.

Financial support. This research received no specific grant from any funding agency, commercial or not-for-profit sectors.

Conflicts of interest. None.

\section{Reference}

1. Nordmeyer S, Krettek S, Nordmeyer J, et al. Fontan completion during winter season is not associated with higher mortality or morbidity in the early post-operative period. Cardiol Young 2020; 30: 629-632. 